\title{
Hacia los Orígenes de una Literatura Colonial
}

La primera descripción de América es aquélla que Colón deja en las páginas de su Diaria, cuando el día 12 de octubre se encuentra, por fin, ante la presencia de tierras, si ignotas, ya anunciadas en la geografía, en la literatura y en las Escrituras. En efecto, no pocos habian trabajado por buscarle una forma a la idea $y$, a juzgar por las anotaciones que el Almirante hizo en los márgenes de sus lecturas anteriores al viaje, no hay duda de que está bien al tanto de la vieja leyenda que en buena medida es la que lo lanza al océano. ${ }^{1}$

Alfonso Reyes nos enseña que tan temprano como unos tres mil años antes de Cristo la fantasía ya andaba prefigurando tierras hacia el Occidente. Confirman la aseveración desde una serie de menciones bíblicas hasta el Dante en pasajes de su Purgatorio. ${ }^{2}$

A pesar de estas indicaciones y aun creyendo en ellas, el navegante se decide a cruzar el Mar de las Tinieblas pensando en llegar a la India, y cuando se encuentra con dudosas islas, afirma que está en Asia, al fin de Oriente. Los geógrafos que había leído así se lo indicaban. De este modo se apoyó en una suposición de la que nunca se desprendería, y "el fundamento de la suposición / era/, pues, la imagen del mundo que el Almirante traía en la cabeza, la premisa básica del viaje". ${ }^{3}$ Y cono-

1 Sobre la formación de Colón y sus lecturas, vid: Samuel Eliot Morison. El Almzirante de la mar Océano (Buenos Aires, 1945), pp. 93-119.

${ }^{2}$ Cfr. Julio Imbelloni. "Las profecías de América, y el ingreso de la Atlántida en la americanística". Boletín de la Academia Nacional de la Historia (Buenos Aires, vol. XII, 1939), pp. 115-148. En este indispensable artículo Imbelloni menciona cuatro "profecías": la que hay en la Medea de Séneca, las del Timeo de Platón, las del Dante y las bíblicas; pero hablando de estas últimas considera sólo las de I Reyes, sin siquiera mencionar por ejemplo, las de Isaías, que tan en mente tuvo el Almirante. Alfonso Reyes se refjere al tema de las profecías en La última Tule (México, 1945), pp. 11-32. Obras completas, vol. XI.

3 Edmundo O'Gorman, La invención de 'América. El universalismo de la cultura de Occidenté (México, 1958), p. 32. 
cedor de las muchas leyendas y profecías sobre la existencia de lejanas comarcas más allá de la geografía conocida, las tintas con que describe su hallazgo corresponden también a la imagen previa, a la que traía en su imaginación: Ofir, el dorado Catay, el Paraíso Terrenal, "la isla de Cipango, de que se cuentan cosas maravillosas", etc. ${ }^{1}$

La descripción ultra-positiva era inevitable. El lugar recién encontrado tendía a superar lo esperado; ahí estaban las nuevas playas of reciendo una identidad: paisajes de sobrecogedora belleza, clima como inmortal primavera y viviendo allí hombres desnudos y hermosos y, entre ellos, "ni tuya ni mío", como cree el Almirante. Así lo que Colón describe tiene de atrayente que es al mismo tiempo una formulación de viejos sueños del hombre que se habían transformado ya en nada más que apreciadas fórmulas de la literatura. ${ }^{5} \mathrm{Y}$ para muchos, especialmente para los humanistas europeos tan ligados a las raíces de lo que iban a ser nuestras letras, el territorio recién encontrado se prestaba como el mejor campo para experimento de los más altos ideales de la humanidad como nunca antes se había of recido. Su presencia física vino a alentar cualquicr tipo de aspiración porque su encuentro era producto de una cultura que lo había prefigurado. ${ }^{6} \mathrm{La}$ idea de la existencia de un otro mundo en éste de la tierra, cobraba gran vigor en la Europa renacentista. Burckhardt, entre los primeros, precisó hace tiempo el profundo cambio de valores que ese movimiento había generado junto con crear un sistema más audaz de concebir el universo y sus cosas.

Nace un impulso por hacer entrar en la geografía tierras de las que hay clara sospecha. Desde que los portugueses comenzaron a descender por las costas de Africa, el mundo queda abierto para ser explorado y conocido en su totalidad. Al abrirse la ruta de los mares aparece un grupo de insignes viajeros y singulares empresarios entre los cuales Colón se alza el más alto al romper la vieja concepción místico-geográfica de que la tierra estaba dividida en tres partes. ${ }^{7}$

4 Cristóbal Colón, Los cuatro riajes del Almirante y su testamento (Madrid, $1964)$, p. 46.

5 "Rappresentando una natura di aspetto favoloso, reale o fantastica, il poeta e il navigatore seguivano uno schema letteratio che la poesia latina e volgate del Medio Evo era andata formando in una secolare costanza di struttura". Leonardo Olschki. Storia letterarta delle scoperte geografiche (Firenze, 1937), p. 17.

Howard Rollin Patch ( $\mathrm{El}$ otro mundo en la literatura medieval, México, 1956), se detiene con detalle en el tema. Vid, especialmente, el Capítulo V, "Viajes al Paraíso".

6 "A partir de este instante, el destino de América comienza a definirse a los ojos de la humanidad como posible campo donde realizar una justicia más igual, una libertad mejor entendida, una felicidad más completa y mejor repartida entre los hombres, una soñada república, una Utopía." Reyes, op. cit., p. 58.

7 "Colón es sóló el más grande de toda una serie de navegantes que surcaron 
Como se advierte, la tradición que apoyaba el necesario encuentro de América era fuerte. Circunstancias de la historia y de la leyenda se dan cita en la tarea. Los sueños del Jardín de Edén, de la Atlántida y de la Antilia se empeñan en reclamar un lugar en las tierras recién encontradas. Los mitos más optimistas se relacionaron a estos suelos desde que el Almirante describe a sus hombres en inocente desnudez. Viejas leyendas estaban esperando el encuentro para pasar a investir a la recién hallada. Así se bautizó a América y toda la imaginería del viejo mundo se puso al servicio de la novedosa tarea; y en éste darle un ser se la fue inventando coma una imagen mejorada de la vieja Europa. ¿Era, entonces, América un universo deseado antes de cobrar existencia? ¿Era la tierra que se buscaba desde los tiempos bíblicos? Cualquiera que sea la respuesta, es claro que se trata de un anhelo viejo de la humanidad, revitalizado por las inquietudes renacentistas. De este modo su descubrimiento dio lugar a la resurrección de las utopías olvidadas desde los tiempos de Platón. ${ }^{3}$

Así es como se comienza a sugerir cuál podría ser la misión de las tierras recién encontradas. El erasmismo pasa al Nuevo Mundo con un vigor mayor al que tenía en la Península. Las autoridades que envía la Iglesia piensan en un cristianismo primitivo (Zumárraga, Las Casas); "Nacer a vida nueva, como partícipe de lo divino, era la única manera de superar la sofística de los teólogos profesionales, acabando al mismo tiempo con el fariseísmo avasallador de la moral y de la religión". ${ }^{10}$ Los elevados propósitos Ilegan incluso a ponerse en práctica: Vasco de Quiroga organiza sus comunidades indígenas de Michoacán siguiendo el modelo

mares lejanos e incógnitos al servicio de los pueblos de Occidente". Jacob Burckhardt. La culturit del Renacimiento en Italia (Barcelona, 1964), p. 210. Sobre esa "edad de reconocimiento". vid: John H. Parry, La época de los descubrimientos geográficos, 1450-1620. (Madrid, 1963). Sobre la concepción místico-geográfica, O'Gorman, op. cit., pp. 105-107.

8 La base sobre la cual se apoya nuestro modo de entender América se origina, principalmente, en el ya citado libro de O'Gorman y en su La idea del descubrimiento de America. Historia de esa interpretación critica $y$ de sus fandamentos (México, 1951).

9 "Los descubrimientos geográficos proporcionaron a la tendencia naturalista y depuradora del Renacimiento una ocasión propicia de ejercicio: Europa, por su vejez, se estimaba difícilmente corregible; pero la humanidad descubierta, desnuda, sencilla, ingenua, podía vivir de acuerdo a la anhelada perfección". Silvio Zavala, La Utopía de Tomás Moro en la Nueva España (México, 1937), p. 4.

1.o Marcel Bataillon, "Prólogo". Erasmo. El Enquiridión o manual del caballer". cristiano (Madrid, 1932), p. 9. Para la vigencia de Erasmo en América, vid, del mismo Bataillón, Erasmo y España (México, 1966). En especial el Apéndice "Erasmo en el Nuevo Mundo". Sobre Moro, además de la ya citada obra de Zavala, vid su Ideario de" Vasco de Quiroga (México, 1941) y su artículo "Letras de Utopía" (Cuadernos Americands, Núm. 2, 1942), pp. 146-152. 
propuesto por el célebre Moro. América es vista como el lugar donde realizar la soñada Utopía.

Colón, pues, había despertado ese optimismo, y bajo el impulso de la tradición, genera un aspecto legendario del Nuevo Mundo. Cada viajero posterior tiende a confirmar la imagen primera disminuyende los pesados trabajos de la empresa.

Es indudable que el novel continente aparece como una proyección de un deseo europeo. Europa descubre América porque la necesita. La época crítica que el viejo mundo está viviendo a fines del mil cuatrocientos demanda nuevos horizontes donde se dé la posibilidad de la reivindicación. ${ }^{11} \mathrm{Y}$ como hay fe en que el Nuevo Mundo será el asiento de todas esas aspiraciones, es que el hombre europeo llega a América viendo sólo aquéllo que quería ver. $Y$ anhelante de encontrarse con aquello que ya había prefigurado en su imaginación comienza describiendo el continente de una forma acorde con el pensamiento previo, y así empieza a nacer una literatura de suyo particular. Una literatura que, como dice Octavio Paz, tuvo que levantarse contra una realidad que era una Utopía. ${ }^{12} \mathrm{Y}$ este rasgo de ser creación premeditada, de ser utopía forjada a fuerza de leyendas y cuentos y desventuras del Viejo Mundo en crisis, dejó su particularidad marcada en las primeras letras de Hispanoamérica. Acaso por tanta leyenda se perdió un rasgo de originalidad que nos hubiera permitido una visión más nítida de lo que fueron, por ejemplo, las culturas precolombinas y el intra-mundo de esos pueblos. Pero tampoco pueden levantarse reclamos protestando que todo lo que pudo ser original se sacrificó en manos de tanta tradición europea. La historia, la crónica, han conservado un caudal valioso de lo nativo, a pesar

11 "Antes de esta época América, aunque existía como continente, no había preocupado a Europa. .. Antes de este momento histótico el europeo había mostrado un gran respeto por lo desconocido... Un buen día se encontró flotando sobre el vacío. Falto de fe todo su mundo se d'errumbaba, entraba en crisis. El ideal situado en lo alto se desvanecía, se alejaba tanto que se hacía inalcanzable. Había que buscar nuevos ideales... y nuevos lugares dónde colocarlos. Ya no podían ser colocados en el cielo. Gracias a la Nueva. Física el cielo dejaba de alojar ideales para convertirse en algo frio e ilimitado, en un infinito muerto, mecánico. $Y$ ese otro lugar no iba a ser otro que la tierra, el mundo... Todo lo que el curopeo necesitaba, todo lo que anhelaba, todo aquello de que carecía, fue colocado en estas tierras desconocidas". Leopoldo Zea, En torno a und filosof'́a Aniericana (México, 1945). p. 9. Vuelve al tema en América én su bistoria (México, 1957).

12 "No se nos puede entender si se olvida que somos un capítulo de la historia de las utopías europeas. No es necesario remontarse hasta Tomás Moro o Campanella para comprobar el carácter utópico de América. Basta con recordar que Europa es el punto, involuntario en cierto modo, de la historia europea, mientras que nosotros somos una creación premeditada". Octavio Paz, "Literatura de fundación", en Puertas al campo (México, 1966), p. 13. 
de estar escrito en castellano; y es en ese cruce inevitable en donde radica buena parte de su calidad.

El Nuevo Mundo se levantó así como suma de todas las perfecciones. La imagen de que se trataba de una Tierra de Promisión persistió a pesar de los sufrimientos que causaba una realidad bastante más dura que la leyenda. Surgió la decepción, pero el mito supo adecuarse a los inconvenientes y salió triunfante. En varios casos el recién llegado protestó con el regreso, pero siempre fueron más los que querían venir y los que se quedaron. ${ }^{13}$

Esta gestación utopista que se relaciona a la fundación del Nuevo Mundo crea, justamente con lo que Zea llama "inadaptación", una actitud literaria que siguió considerando a esta tierra como el lugar prometido, como un remanso en el transcurso del tiempo en el cual se habría guarecido la perdida Edad de Oro. De manera que esta experiencia del hombre europeo se transforma en una "visión del mundo" que hasta Ios escritores criollos compartieron y prolongaron a través de nuestras primeras letras. ${ }^{14}$ Podríamos decir que en todo caso, hay un desborde de la imaginación y que ese desborde ocurre por igual en los de aquél y en los de este lado del océano. Apenas veinticuatro años después de la llegada de Colón por estas playas, Tomás Moro -mencionando los viajes de Vespuccio- da a luz una obra que, estamos ciertos, no es nada ajena a un espíritu vital que uniforma la literatura de la Colonia hasta más allá de la Ilustración.

Desde la primera descripción, ultra positiva, que el Almirante hace de América, la leyenda comienza a cobrar vida, los viajeros que inmediatamente le continúan confirman los primeros hallazgos, y otros en Eutopa se ocupan de depurar lo que se cuenta, como Mártir de Anglería, por ejemplo. ${ }^{15}$

Además, los hombres que vinieron a animar la vida colonial eran lectores creyentes de un cierto tipo de ficción relacionada - principalmente- con las aventuras. Aquellos hombres cuya fantasía, cuyo margen

13 "El europeo, atraído a estas tierras por la leyenda, iba pronto a saber esto. La decepción habría de surgir pronto, y con ella la inadaptación del americano. Sin cmbargo, para Europa, esta América siguió siendo tierra de promisión, tierra nueva. La fantasía europea siguió bordando sobre América. Amética no era así que otra cosa que una creación utópica de Europa". Zea, op. cit., pp. 48-49.

14 Como se sabe, el mito d'e la Edad de Oro ronda al Nuevo Mundo antes y después de octubre de 1492 . La vigencia renacentista del tema es clara y su relación con Amética, inevitable. Vid: Harry Levin, The Myth of the Golden Age in the Renaissance (New York, 1969).

${ }_{15} \mathrm{La}$ influencia de Mártir de Angleria y su relación con Tomás Moro ha sido vista con brillo por Ezequiel Martínez Estrada en "El Nuevo Mundo, Ia isla de Utopía y la isla de Cuba" (Cuadernos Americanos, Núm. 2, 1963), pp. 89-122. 
de capacidad imaginativa había sido ampliado por los contenidos de esos libros aventuretos, continúan buscando la adecuación de América con ei universo fantástico que les muestran sus lecturas, y el Nuevo Munda, en más de una medida, tesponde a esa petición. ${ }^{16}$ Era ansia de palpar con manos propias lo que se conocía a través de seductoras historias. Célebre es el momento cuando Bernal Díaz se detiene ante la presencia de la cercara Tenochtitlan y dice que ésta es superior a aquéllas de que habla el Amadís. ${ }^{17} \mathrm{El}$ ámbito de las caballerías tenía que existir en algún lugar y así, más por curiosidad que por honor, un contingente de Bernales comienza a llegar a Indias. La fauna, la flora y la geografía de toda clase de leyendas empieza a encontrar su rincón en América.

La desesperada búsqueda de El Dorado, de la Fuente de la Juventud, de la Ciudad de los Césares, de las minas del Rey Salomón, es una confirmación pintoresca de que ese sentimiento sobre el Nuevo Mundo era bastante serio. Pero, contra toda imaginación, semejantes lugares no fueron nunca encontrados en nuestros territorios. El mito eludía, una y otra vez a las legiones de ansiosos exploradores. Entonces, ¿por qué se persistía en su búsqueda? ¿Qué mantenía viva la fe del buscador? Acaso, comprobando la imposibilidad de encontrar tales regiones, esos hombres dejaron en la literatura los contenidos que no pudieron quedar en la Historia. Esas creaciones insólitas siguieron viviendo sólo en el terreno de las letras. La Crónica de América, como ha dicho Carpentier, se tornó en la crónica de lo real maravilloso y, todavía en pleno Siglo de la Razón, se seguía buscando la perdida Ciudad de los Césares. El nuevo continente aportó su propia maravilla y junto a ella se adecuó la que venía de Europa. ${ }^{18} \mathrm{La}$ interacción entre literatura y realidad, entre creencias y hechos se va resolviendo en favor de la fantasía, de la imaginación. La imagen que había legado Colón no muere: lucha y permanece en pie guardando para sí un buen terreno en las páginas de la literatura Colonial.

Es cierto que esta carencia de deslinde significó confusión; pero

16 "Se han dado ya algunas indicaciones acerca del poderoso ascendiente que tenían los librois de caballerías sobre la mente popular en la primera mitad del siglo XVI. La influencia de esta literatura sobre el pensamiento y la acción de los lectores es incuestionable aunque no se la puede medir con exactitud. El conquistador como elemento aventurero y dinámico de la sociedad española, mal podía escapar a la incitación de semejantes fantasias." Irving Leonard, Los libros del Conquistador (México, 1953), p. 36.

17. Cfr. Stephen Gilman, "Bernal Díaz del Castillo and Amadís Gaula". Separata del Homenaje a Dámaso Alonso (Madrid, 1961), pp. 99-114.

18 Vid: "De lo real maravilloso americano", en Tientos y diferencias (2a. Ed. Montevideo, 1970), pp. 96-112. También sobre este tema véanse los primeros capítulos de Francisco Esteve Barba. Histariografía indiana (Madrid, 1964). 
tanto creadores como lectores no lo entendieron así. Eso era lo que se esperaba. Leonard sostiene que el pueblo español, ebrio de triunfos y en posesión de la idea que tenía un destino privilegiado, vivía llano a aceptar todos los relatos de grandes hazañas y portentosos encuentros que sus magníficos héroes estaban llamados a realizar. Este pensamiento es uno de los pilares sobre los cuales se apoya la literatura de los siglos coloniales. ${ }^{19}$

De manera que el criterio de "lo visto y lo vivido" como indicador único de verdad en lo que se cuenta, hace agua debido al peculiar nacimiento de esta literatura. "Lo visto y lo vivido", se ha dicho, es un modo de manifestar "esto es verdad, yo lo vi, no es parte de la leyenda"; pero, ¿qué sucede cuando se afirman como "vistos y vividos" milagros que dejarían chicos a los de las Escrituras? Y los hay desde Cortés hasta Garcilaso.

Es claro que el grado de delimitación no cuenta mucho en estas letras. Lo que hay de "real" en la literatura de la época no se debe a que el autor no lo viera o lo viviera, se debe a que toda una concepción del mundo es todavía parte del reino de la ficción. La imaginación tiene entonces el dominio sobre la mitad del saber humano. Fantasía y realidad se fueron mezclando - y no podía ser de otra manera - hasta dar como resultado toda una historia cuyos límites eran bastante imprecisos: estaban al borde de la ficción. Tampoco importaba señalar esos límites. El criterio riguroso que separa nítidamente la historia de la poesía, a pesar de su origen, es más bien moderno. Por entonces no contaba; al menos no contaba cuando se trató del Nuevo Mundo. Asi fue como permanecieron en pie los mitos más depurados, las creencias más bellas, poblando páginas que ora estaban en la historia, ora en la literatura.

Pero es clato que América no ofrecía de hecho un paraíso a los ilusos que cruzaban el océano para llegar a encontrarlo. La otra cara de la moneda era bastante brutal; sin olvidar tampoco que los conquistadores trajeron también mucho de lo peor que la crítica sociedad europea se había encargado de generar. A pesar de todo eso, las grandes leyendas supieron prevalecer: no hay más que mirar a Ercilla, a Balbuena, al Inca Garcilaso, a Oña, a Ovalle para darse cuenta de la efectividad de la afirmación.

$Y$ si el de Colón había sido un falso sueño, y si la imagen de un paraíso ubicado en suelos del Nuevo Mundo iba perdiendo vigencia, los escritores se dieron a la heroica tarea de mantenerla viva. Había en ellos, necesario es reconocerlo, una fuerte dosis de interés personal: querían

19 Cf. Leonard, op. cis., p. 38. 
mostrar a las Autoridades con qué arrojo venían a ejecutar valientes hazañas en este mundo mitad ficción mitad infierno.

La semilla, de la Edad de Oro puesta en tierras del Nuevo Mundo siguió aquí fructificando por el vigor de la pluma y luego con renovada energía en Europa - Montaigne es el ejemplo más sólido al respecto. Nadie retrocedió en la empresa, ni la Corona que ya había comprometido en punto avanzado su prestigio político y religioso ni los hombres de letras que ya habían comprometido el suyo en pos del símil América: Arcadia. En el momento en que las utopías comenzaban a ser deseadas con ardor y en que el paraíso Terrenal era intuido por los cartógrafos, el Almirante, según se lo indica su carta de marear - y más que eso, casi todas las tradiciones europeas- da los primeros avisos del encuentro. Y a partir de ese preciso momento empieza a nacer la literatura colonial de Hispanoamérica.

JuAN Durán Luzio

Harvard University 